Johns, A. T. (1951). J. gen. Microbiol. 5, 317-325.

\title{
Isolation of a Bacterium, Producing Propionic Acid, from the Rumen of Sheep
}

\author{
By A. T. JOHNS* \\ Biochemistry Department and Agricultural Research Council Unit of Animal \\ Physiology, University of Cambridge
}

SUMMARY: A strictly anaerobic micrococcus which produces acetic acid, propionic acid, carbon dioxide and hydrogen by fermentation of lactate was isolated from the rumen of sheep. It failed to ferment sugars and was identified as Veillonella gazogenes. Its significance in ruminant digestion is uncertain, but a characteristic reaction of this organism, the decarboxylation of succinic acid to yield propionic acid and carbon dioxide, appears to be important in the rumen. This reaction was studied by the Warburg technique with washed suspensions of rumen bacteria.

It had been known for a considerable time that volatile acids were amongst the products of rumen fermentation of plant material, but it was not until Elsden (1946) developed a partition chromatographic method which separated quantitatively mixtures of fatty acids that their identity was definitely established. Acetic, propionic and butyric acids were always found and traces of higher acids were sometimes detected. Very little is known about the microorganisms responsible for the digestion of carbohydrate in the ruminant or of the metabolism of the organisms active in rumen fermentation. It is now generally agreed that the main role in rumen fermentation is played by bacteria, since the removal of protozoa by drenching with dilute copper sulphate has little effect on the digestive process (van der Wath, 1942).

Most of the attempts to isolate organisms responsible for the chemical changes in the rumen were made on digesters of cellulose. The most successful approach to this difficult problem was made by Hungate $(1946,1947)$. In the present work an attempt was made to isolate organisms responsible for the production of propionic acid in the rumen of sheep. Elsden (1945) isolated, from celluloseenrichment cultures of rumen contents, bacteria which appeared to be members of the genus Propionibacterium and which he believed were responsible for the formation of the propionic acid invariably found in the rumen. Elsden stated that: 'Under the conditions used, the fermentation of cellulose appears to be a two-stage process, a primary breakdown of cellulose by the specific organisms followed by a secondary fermentation of the product or products thus formed by the propionic acid bacteria.' Since all propionic acid organisms so far isolated ferment lactic acid, with the exception of Propionibacterium acnes (Douglas \& Gunter, 1946), and since lactic acid appears under certain circumstances (Phillipson, 1942) to be an intermediate in the fermentation of cellulose to volatile fatty acids in the rumen, it seemed logical to use enrichment cultures with sodium lactate as source of carbon for isolating the organisms responsible

* Present address: Plant Chemistry Laboratory, D.S.I.R., Palmerston North, New Zealand. 
for propionic acid production in the rumen. Further, since the conditions in the rumen favour the growth of anaerobic bacteria, the enrichment cultures were incubated anerobically.

\section{EXPERIMENTAL}

\section{Methods}

Isolation of bacteria. Glass-stoppered bottles of about $80 \mathrm{ml}$. capacity were filled with medium which was composed of the general purpose salt mixture of Stephenson (1949), with $0 \cdot 4 \%$ (w/v) Difco yeast extract and $1 \%(\mathrm{v} / \mathrm{v})$ sodium lactate, adjusted to $\mathrm{pH} 7$. For the first enrichment $5 \mathrm{ml}$. of rumen contents, obtained from sheep with a permanent rumen fistula, were added to the bottles and the stoppers inserted so that no air bubbles were trapped. The bottles were incubated at $37^{\circ}$ for $24 \mathrm{hr}$., by which time turbidity was evident and considerable evolution of gas had occurred. Two transfers were made at $24 \mathrm{hr}$. intervals using the same medium. Bacteria were isolated by plating on enrichment media solidified with $2 \%(\mathrm{w} / \mathrm{v})$ agar. The plates were incubated in a McIntosh \& Fildes jar in an atmosphere of $95 \% \mathrm{H}_{2}+5 \% \mathrm{CO}_{2}$. Growth of colonies was definitely better in this mixture than in pure hydrogen.

Determination of number of bacteria. The number of lactate-fermenting anaerobic bacteria present in rumen contents was determined by a serial dilution method using two series of tubes, one series $(a)$ containing enrichment medium and the other $(b)$ enrichment medium without lactate. Nineteen $\mathrm{ml}$. of the medium $+2 \%(\mathrm{w} / \mathrm{v})$ agar $+0.02 \%(\mathrm{w} / \mathrm{v}) \mathrm{Na}_{2} \mathrm{~S} .9 \mathrm{H}_{2} \mathrm{O}$ were placed in test-tubes. The tubes were kept at a temperature of $50^{\circ}$, rumen contents (1.0 ml.) added, the solution thoroughly mixed, a $1 \mathrm{ml}$. sample withdrawn under sterile conditions and added to a second tube containing $19 \mathrm{ml}$. of the medium and so on for ten dilutions. The tubes were incubated anaerobically at $37^{\circ}$ for $48 \mathrm{hr}$. The number of colonies present in the lowest dilution showing growth was noted. The agar was expelled from the tubes and the colonies at the lowest dilution picked out, Gram-stained and examined microscopically.

Preparation of washed suspensions of rumen organisms. Rumen contents were strained through muslin and differentially centrifuged as follows. The centrifuge was allowed to reach 200 r.p.m., and then switched off. A large proportion of the plant material had then settled down. The supernatant was next centrifuged at 2000 r.p.m. for $5 \mathrm{~min}$., removing the remaining plant material, protozoa and some large bacteria. The supernatant was then centrifuged for $30 \mathrm{~min}$. at 2000 r.p.m. and the resulting bacterial deposit resuspended in distilled water containing $0.02 \%(w / v) \mathrm{Na}_{2} \mathrm{~S} .9 \mathrm{H}_{2} \mathrm{O}$. This was spun down yielding a bacterial deposit equivalent to $c .0 .5 \mathrm{~g}$. dry weight bacteria per $500 \mathrm{ml}$. rumen contents. These bacteria were taken up in distilled water containing $0.02 \%(\mathrm{w} / \mathrm{v}) \mathrm{Na}_{2} \mathrm{~S} .9 \mathrm{H}_{2} \mathrm{O}$.

Lactic acid was determined by the method of Friedemann \& Graeser (1933).

Propionic and acetic acids were identified and estimated by the silica gel partition chromatographic method of Elsden (1946). Martin \& Synge (1941) showed that $R$, the ratio between the rate of movement of a compound down the column and the rate of movement of the developing solvent in the tube, 
is related to the partition coefficient of the compound between the water and the non-polar phase. The value of $R$ is thus characteristic of the compound. In the case of the volatile fatty acids the $R$ values vary with the concentration, and with different batches of silica gel (Elsden, 1946). In identifying acids it was thus necessary to determine both the concentration and the corresponding $\boldsymbol{R}$ value for the particular preparation of silica gel. The individual acids after resolution on silica gel were chromatographed together with known acids as markers to verify the identifications.

Apparatus for fermentation-balance experiment. The fermentation was carried out in a flask attached to a mercury-filled manometer connected to an adjustable reservoir, which was adjusted to keep the gas at atmospheric pressure. It was so arranged that after inoculation under sterile conditions the apparatus could be filled with sterile nitrogen. The volume of gas produced by fermentation included that indicated by the mercury manometer and the dissolved gas in the liquid (mainly $\mathrm{CO}_{2}$ ) which was determined in the van Slyke manometric gas-analysis apparatus. The gas in the manometer was analysed by means of the Haldane gas-analysis apparatus.

\section{Characters of bacteria isolated}

The colonies formed on the agar plates were all of the same kind, clear, convex, smooth, circular and entire, greyish white by reflected light and of characteristic honey colour by transmitted light. The cells were spherical, $0 \cdot 3-0 \cdot 6 \mu$. in diameter, occurring singly, in pairs and in large irregular groups; Gram-positive in young cultures but Gram-negative after 12-18 hr. growth. The organism did not liquefy gelatine, was non-haemolytic, $\mathrm{H}_{2} \mathrm{~S}$ positive, indole negative and reduced nitrate to nitrite. Most strains appeared to be weakly catalase positive but this varied from strain to strain. Strictly anaerobic conditions were essential for growth, with temperature and $\mathrm{pH}$ optima $37^{\circ}$ and 6.0-8.0 respectively. The following compounds were fermented vigorously: DL-lactate, pyruvate, L-malate, fumarate and $D$-tartrate.

The following compounds were not fermented: glucose, fructose, arabinose, L-xylose, galactose, mannose, maltose, L-sorbose, sucrose, lactose, raffinose, rhamnose, inulin, starch, glycerol, dextrin, mannitol, salicin, citrate, erythritol, DL-serine, alanine, glutamic acid, glycine, methionine, L-cystine, tryptophan, sodium formate.

From these characters it seemed likely that these organisms were similar to the Gram-negative anaerobic micrococci isolated from saliva by Hall \& Howitt (1925). Hall \& Howitt considered these organisms to be identical with Micrococcus alcalescens anaerobius described by Lewkowicz (1901) and renamed it M. gazogenes. Bergey (1948) adopted the classification of Prévot (1933) who placed it in the genus Veillonella of the family Neisseriaceae.

Strains of Veillonella gazogenes (alcalescens var. Fay) obtained from Dr A. R. Prévot were identical in fermentation tests and staining reactions with the strains isolated in the present investigation. The products of lactate fermentation were also identical, i.e. lactate was fermented to $\mathrm{H}_{2}, \mathrm{CO}_{2}$, acetate and propionate. Foubert \& Douglas $(1948 a)$ obtained from tonsils anaerobic micro- 
cocci which gave these fermentation products with lactate as substrate and which they considered to be identical with $V$.gazogenes. They observed that the organism was Gram-positive in young cultures, making it ineligible for classification under the family Neisseriaceae, and they suggested transferring it to the genus Micrococcus, giving it the species name lactilyticus.

It is believed that the micrococcus isolated from the rumen in the present work is Veillonella gazogenes. It was found in the rumen of all sheep examined and was isolated from sheep saliva and from the human mouth. Elsden \& Volcani (private communication) isolated two strains with similar properties from the rumen of sheep in California.

\section{Fermentation balance experiments}

Table 1 gives the result of a typical balance experiment carried out with strains of Veillonella $((a)$ isolated from the rumen of a sheep; $(b)$ Dr Prévot's organism) in the lactate medium used for isolating the bacteria.

Table 1. Products of fermentation of lactate by Veillonella strains at $37^{\circ}$ Concentrations of products are given in $\mathrm{mmol} . / 100 \mathrm{mmol}$. lactate fermented.

\begin{tabular}{|c|c|c|}
\hline & Sour & nism \\
\hline & & Institut \\
\hline Products & Rumen & Pasteur \\
\hline Propionic acid & $58 \cdot 5$ & $56 \cdot 0$ \\
\hline Acetic acid & $48 \cdot 7$ & $45 \cdot 0$ \\
\hline Carbon dioxide & $\mathbf{3 5} \cdot \mathbf{2}$ & $\mathbf{3 8} \cdot \mathbf{0}$ \\
\hline Hydrogen & $14 \cdot 8$ & $22 \cdot 4$ \\
\hline Carbon recovery (\%) & $102 \cdot 0$ & 98.5 \\
\hline Redox index & $1 \cdot 04$ & $1 \cdot 07$ \\
\hline
\end{tabular}

The oxidation-reduction (redox) index was calculated by the method introduced by Johnson, Peterson \& Fred (1931). It is important to calculate the redox balance as well as the carbon balance as it gives an indication whether a product has been overlooked; it may also give an indication of $\mathrm{CO}_{2}$ fixation (Wood \& Werkman, 1936).

The results in Table 1 are similar to those obtained by Foubert \& Douglas $(\mathbf{1 9 4 8 b})$ with the organism they designated Micrococcus lactilyticus. It will be shown in a subsequent paper that the ratio in which the products are obtained is not a constant, but is dependent on the $\mathrm{CO}_{2}$ concentration in the medium.

Both the Veillonella strains isolated from the rumen and those obtained from Dr Prévot grew profusely on D-tartrate. A balance experiment was carried out using a Veillonella strain from the rumen and D-tartrate as the source of carbon (Table 2).

Table 2. Fermentation of $\mathrm{D}$-tartrate by a Veillonella strain from the rumen Concentrations of products are given in mmol./100 mmol. of D-tartrate fermented.

$\begin{array}{lclc}\text { Propionic acid } & \mathbf{8 \cdot 8} & \text { Carbon dioxide } & \mathbf{1 7 4} \cdot 0 \\ \text { Acetic acid } & \mathbf{9 5} \cdot 4 & \text { Hydrogen } & \mathbf{7 4} \cdot 0 \\ \text { Carbon recovery (\%) } & \mathbf{9 7} \cdot 7 & \text { Redox index } & \mathbf{1} \cdot 10\end{array}$




\section{Importance of Veillonella in the rumen}

The rumen population contains such a great variety of microbial species that mere isolation of an organism from rumen contents gives no information about its function in digestion. Elsden \& Phillipson (1948) remarked that "Two criteria must be fulfilled before an organism can be said to be a functional member of the rumen population: $(a)$ the organism must perform a chemical reaction known to occur in the rumen; $(b)$ the organism must be present in

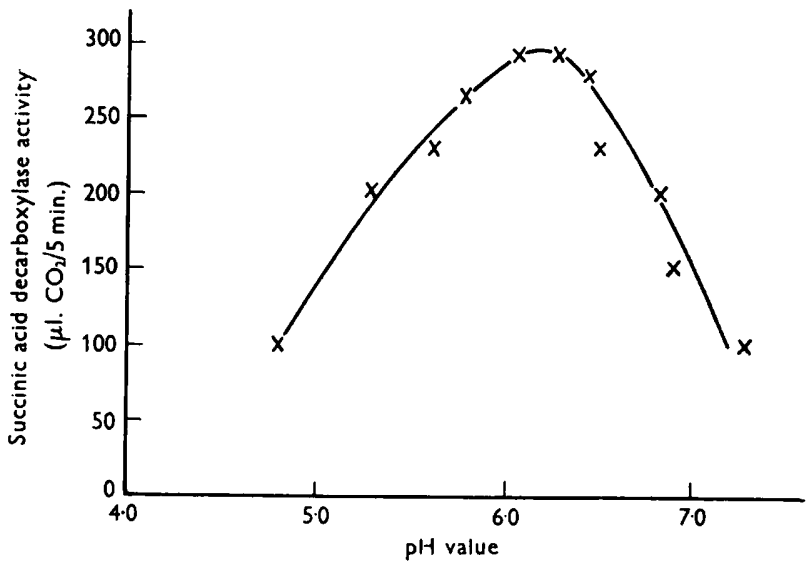

Fig. 1. Succinic acid decarboxylase activity of rumen bacteria at different pH values. Manometers contained: $1 \mathrm{ml}$. of bacterial suspension, $22 \mathrm{mg}$. dry weight $/ \mathrm{ml}$; 1.6 ml. buffer $0.067 \mathrm{M}$ phosphate, or phthalate below pH $5 \cdot 3$ (main compartment); $0.2 \mathrm{ml} .0 \cdot 1 \mathrm{M}$ succinate (side bulb 1); $0.2 \mathrm{ml}$. $2 \mathrm{~N}-\mathrm{H}_{2} \mathrm{SO}_{4}$ (side bulb 2); gas phase $\mathrm{N}_{2}$; temp. $37^{\circ}$. Two manometers at each $\mathrm{pH}$; in one, acid tip at start, in other, acid tip after $5 \mathrm{~min}$.

sufficient numbers to perform this reaction.' Criterion $(b)$ might be modified to read: the organism must be present in sufficient numbers to perform this reaction extensively enough to account for a considerable part of the reaction rate observed in the rumen. With regard to criterion $(a)$ it was shown that washed suspensions of Veillonella isolated from the rumen (Johns, 1948, 1949) characteristically and rapidly decarboxylated succinic acid and gave a quantitative yield of propionic acid and $\mathrm{CO}_{2}$. The optimum $\mathrm{pH}$ for this reaction was between 5.9 and 6.0, with $Q_{\mathrm{CO}_{2}} 270-300$. If $V$. gazogenes is present in large numbers in the rumen it would be expected that washed suspensions of rumen bacteria would also show decarboxylase activity with a similar $\mathrm{pH}$ optimum.

Rumen contents were obtained from sheep $16 \mathrm{hr}$. after having been taken off winter pasture (July) in New Zealand. The washed suspension obtained was tested for succinic decarboxylase activity by the Warburg technique. At pH 6.0 it was found that sodium succinate was quantitatively decarboxylated to propionic acid and $\mathrm{CO}_{2}$. This experiment was repeated at different $\mathrm{pH}$ values (Fig. 1). From pH 5 to 7 there was considerable activity with a $\mathbf{Q}_{\mathrm{co}_{2}}$ of 134 at $\mathrm{pH}$ 6.2. Elsden (private communication) also found that washed suspensions of rumen bacteria decarboxylated succinate. 
The number of Veillonella present was determined by serial dilution in duplicate using $1 \mathrm{ml}$. of rumen contents. The colonies in the lowest dilution were counted and then isolated after breaking the test-tube and expelling the agar into a sterile Petri dish. Determinations on three different animals which had been $16 \mathrm{hr}$. off winter grass gave: $7 \cdot 4 \times 10^{6}, 1 \times 10^{6}, 6 \cdot 2 \times 10^{5}$ organisms $/ \mathrm{ml}$. rumen contents. It is difficult to give comparative figures for other bacteria or even total numbers in the rumen as the methods employed by other workers have been different. Van der Wath $(1942,1948)$, by a counting technique which appeared to give reproducible results, found a total population on a diet of wheat straw of $5 \cdot 8 \times 10^{8} \mathrm{bacteria} / \mathrm{ml}$; w when fish meal was added the population increased to $1.9 \times 10^{9}$ cells $/ \mathrm{ml}$. Johnson et al. (1942) made total counts of a yeast-like organism which develops in the rumen of sheep when lucerne or mangolds are fed and found 2.5-8.3 $\times 10^{7}$ organisms $/ \mathrm{ml}$. Gall, Burroughs, Gerlaugh \& Edgington (1949a) found that bacterial slide counts from cattle and sheep on winter rations averaged about $5 \times 10^{10} / \mathrm{g}$. rumen contents, while on pasture cattle and sheep averaged $9 \cdot 6 \times 10^{10} / \mathrm{g}$. rumen contents and $8 \cdot 54 \times 10^{10} / g$. rumen contents respectively; Gall, Lorraine, Smith, Becker, Stark \& Loosli (1949 b), in a study of cobalt-deficient sheep, give bacterial slide counts in cobalt-fed sheep of $5 \cdot 46 \times 10^{10} / \mathrm{g}$. rumen contents. The slide counts are total counts, of course, and include dead and viable bacteria. These figures appear to be too low for New Zealand conditions, as I have repeatedly found by the serial dilution method an unidentified organism which gives a count of the order of $10^{10} / \mathrm{ml}$. Until further work is done under New Zealand conditions the significance of the Veillonella counts and the degree to which criterion (b) is fulfilled cannot be assessed.

\section{DISCUSSION}

The biochemical changes which are brought about by the rumen microflora have been studied previously in vivo or by incubating rumen contents in vitro. Both methods are open to objections. When a particular substrate is added the natural population balance is upset by the multiplication of these organisms which readily utilize the particular substrate. In vivo sampling errors are a major difficulty, especially with cows, and an unknown amount of substrate end-products is continually being removed by absorption through the rumen wall and by passage down the alimentary canal. Pearson \& Smith (1943), using the microscopical appearance of the bacterial flora and the $\mathrm{pH}$ of material incubated in vitro as criteria, believed that it was still comparable with normal rumen contents after $2-4 \mathrm{hr}$. incubation.

In the present work the washed suspension or 'resting bacteria' technique (Quastel \& Whetham, 1925), which was developed for pure cultures of bacteria, was applied to the mixed culture obtained on centrifuging down rumen contents. This makes use of a rather arbitrary fraction of rumen bacteria according to the centrifuging procedure. Provided the experiment does not last longer than 2-3 hr. multiplication does not occur (Cook \& Stephenson, 1928) as sources of nitrogen are removed by the washing. This technique should be useful for studying carbohydrate metabolism of rumen bacteria and though not yielding 
absolute figures, should, by the use of a standardized technique, give an idea of comparative biochemical activity.

$V$. gazogenes fulfils the first criterion of Elsden \& Phillipson (1948) for determining whether an organism is of significance in the rumen, in that it performs a chemical reaction known to occur there. However, it also gives rise to a considerable amount of hydrogen. Numerous authors have reported small quantities of hydrogen present in rumen gases, but Lugg (1938) in a very careful study found none at all. From the work of Barker (1936) we know that methane is produced by certain bacteria by the reduction of $\mathrm{CO}_{2}$ with hydrogen. The mechanism of methane production in the rumen is unknown, but Elsden (private communication) has found indications that the reduction of $\mathrm{CO}_{2}$ by hydrogen can take place in vitro with rumen contents. If Veillonella species are important in the rumen, they would provide hydrogen for methane production, and this would explain the lack of hydrogen in the rumen gases.

Phillipson (1942) found that the only natural diets to produce detectable amounts of lactate in rumen fermentation are mangolds, and, to a very small extent, oats. When lactate is formed in quantity as an intermediate in fermentation we should expect the conditions to be more favourable for growth of Veillonella. Changes in composition of the rumen flora have been observed to accompany changes in diet so that the only way of determining an organism's significance is to study it in the animal at different times of the year and under different feeding regimes. From counts made on winter grass in New Zealand it seems that Veillonella species are only of moderate importance but comparable counts of other species are not available for a definite decision to be made.

Elsden (1945) believed that members of the genus Propionibacterium were responsible for the formation of propionic acid in the rumen. It appears unlikely that they are important, as Delwiche (1948) and Johns (1949) have shown that members of this genus decarboxylate succinate only slowly, having a $Q_{\mathrm{Co}_{2}}$ of 1-4 at an optimum $\mathrm{pH}$ of $5-5 \cdot 2$ which is far removed from the optimum $\mathrm{pH}$ value for this reaction with rumen contents. No true propionibacteria were isolated by the procedure used in the present investigations, but the incubation periods were far too short to allow growth of Propionibacterium colonies.

There may be a number of bacterial species that play a part in the formation of propionic acid in the rumen as suggested by the spread of the $\mathbf{p H}$ optimum curve in Fig. 1 ; but it appears that the decarboxylation of succinate by washed suspensions of rumen bacteria is rapid enough to explain the propionic acid formation observed (Johns, 1948). It is probable that the dominant organism responsible will vary with the diet.

I am indebted to the late Sir Joseph Barcroft and Prof. I. de Burgh Daly for allowing me to use freely the animals and facilities of the Agricultural Research Council Unit of Animal Physiology. My thanks are due to Dr A. R. Prévot (Institut Pasteur, Paris) for strain Fay of Veillonella gazogenes, and to Dr E. Foubert (Gonzaga University, Washington) for strains of anaerobic micrococci isolated from tonsils, and to Mr Sellars (Animal Pathology Laboratory, Cambridge) for checking 
the fact that Veillonella strains do not ferment sugars. I am greatly indebted to Dr S. R. Elsden for his interest and advice during this work and for reading the proofs.

\section{REFERENCES}

BARKer, H. A. (1936). On the biochemistry of the methane fermentation. Arch. Mikrobiol. 7, 464.

Bergey's Manual of Determinative Bacteriology (1948). 6th edition, ed. by Breed, R. S.. Murray, E. G. D. \& Hitchens, A. P. London: Baillière, Tindall and Cox.

Cook, R. P. \& Stephenson, M. (1928). Bacterial oxidations by molecular oxygen. 1. The aerobic oxidation of glucose and its fermentation products in its relation to the viability of the organism. Biochem. J. 22, 1368.

DeLwiche, E. A. (1948). Mechanism of propionic acid formation by Propionibacterium pentosaceum. J. Bact. 56, 811.

Douglas, H. C. \& Gunter, S. E. (1946). The taxonomic position of Corynebacterium acnes. J. Bact. 52, 15.

Elsden, S. R. (1945). Fermentation of carbohydrates in the rumen of the sheep. J. exp. Biol. 22, 51.

ElsDen, S. R. (1946). Application of the silica gel chromatogram to the estimation of volatile fatty acids. Biochem. J. 40, 252 .

Elsden, S. R. \& Phillipson, A. T. (1948). Ruminant digestion. Ann. Rev. Biochem. $17,557$.

Foubert, E. L. \& Douglas, H. C. (1948a). Studies on the anaerobic micrococci. I. Taxonomic considerations. J. Bact. 56, 25.

Foubert, E. L. \& Douglas, H. C. (1948b). Studies on the anaerobic micrococci. II. Fermentation of lactate by Micrococcus lactilyticus. J. Bact. 56, 35.

Friedemann, T. E. \& Graeser, J. B. (1933). Determination of lactic acid. J. biol. Chem. 100, 291.

Gall, L. S., Burroughs, W., Gerlaugh, P. \& Edgington, B. H. (1949a). Rumen bacteria in cattle and sheep on practical farm rations. J. Anim. Sci. 8, 441.

Gall, L. S., Lorraine, S., Smith, S. E., Becker, D. E., Stark, C. N. \& Loosi, J. K. $(\mathbf{1 9 4 9 b})$. Rumen bacteria in cobalt deficient sheep. Science, 109, 468.

Hall, I. C. \& Howite, Beatrice (1925). Bacterial factors in pyorrhea alveolaris. IV. Micrococcus gazogenes, a minute Gram-negative non-sporulating anaerobe prevalent in human saliva. J. infect. Dis. 37, 112.

Hungate, R. E. (1946). Studies on cellulose fermentation. II. An anaerobic cellulose decomposing Actinomycete, Micromonospora propionici, n.sp. J. Bact. 53, 631.

Hungate, R. E. (1947). Studies on cellulose fermentation. III. The study and culture of cellulose decomposing bacteria from the rumen of cattle. J. Bact. 53, 631.

Johns, A. T. (1948). The production of propionic acid by decarboxylation of succinate in bacterial fermentation. Biochem. J. 42, ii.

Jonss, A. T. (1949). The mechanism of propionic acid formation in bacterial fermentation. Nature, Lond., 164, 620.

Johnson, B. C., Hamilton, T. S., Robinson, W. B. \& Garey, J. C. (1944). Nonprotein nitrogen utilization by ruminants. J. Anim. Sci. 1, 236.

Johnson, M. J., Peterson, W. H. \& Fred, E. B. (1931). Oxidation and reduction relations between substrate and products in the acetone-butyl alcohol fermentation. J. biol. Chem. $91,569$.

Lewkowicz, X. (1901). Recherches sur la flore de la bouche du nourrison. Arch. Méd. exp. 13, 633 .

LUGG, J. W. H. (1938). Identification and measurement of the combustible gases that occur in the gaseous metabolic products of the sheep. J. agric. Sci. 28, 688. 
Martin, A. J. P. \& Synge, R. L. M. (1941). A new form of chromatogram employing two liquid phases. Biochem. J. 35, 1358.

Pearson, R. M. \& Smith, J. A. B. (1943). The utilization of urea in the bovine rumen. Biochem. J. 37, 153.

Phillipson, A. T. (1942). Carbohydrate digestion in the sheep. J. exp. Biol. 19, 186.

Prévot, A. R. (1933). Etudes de systématique bactérienne. I. Lois générales. II. Cocci anaerobies. Ann. sci. nat., Botan. Sér. 10, 15, 23.

Quastel, J. H. \& Whetham, M. D. (1925). Dehydrogenations produced by resting bacteria. Biochem. J. 19, 645.

Stephenson, M. (1949). Bacterial Metabolism, 3rd ed. London: Longmans, Green and Co.

Wath, J. G. van Der (1942). Thesis. University of Pretoria, Union of South Africa.

WATH, J. G. VAN DER (1948). A technique for counting rumen bacteria. Onderstepoort J. vet. Sci. 23, 385.

Woon, H. G. \& Werkman, C. H. (1936). The utilization of $\mathrm{CO}_{2}$ in the dissimilation of glycerol by the propionic acid bacteria. Biochem. J. 30, 48 . 